\title{
Treatment of Crohn's Disease in a Patient With Concomitant Hepatitis C AND HeMophilia
}

\section{Donna Williams, MD}

\section{Introduction}

Treatment of Crohn's disease often involves the use of immunomodulating drugs. Most trials of these drugs have excluded patients with coexisting illness by study design. The purpose of this case report is to describe the treatment of a rare case of Crohn's disease in the face of concomitant hepatitis $\mathrm{C}$ and hemophilia.

\section{Case Presentation}

The patient is a 37 year-old Caucasian male who has a history of severe factor IX deficiency complicated by frequent bleeding into joints, hepatitis $\mathrm{C}$ genotype $1 \mathrm{~b}$ acquired through factor transfusions, and terminal ileal Crohn's disease which was diagnosed by small bowel $x$-ray in 1985 . At that time, he was treated with azulfidine and corticosteroids with some improvement. The patient was maintained on 5-ASA and steroids until 2000, when steroids were tapered in an attempt to prepare him for treatment of his hepatitis C. By May 2001, the patient was off all steroids and was maintained on asacol $1200 \mathrm{mg}$ BID. At that time, liver biopsy revealed liver parenchyma with focal, mild to moderate macrovesicular steatosis. Portal tracts had mild, lymphocytic infiltrate and bile ducts were present without significant epithelial atypia. Due to the benign findings on liver biopsy, the decision was made to defer treatment of hepatitis C.

In the fall of 2001, the patient began to experience episodes of bright red blood per rectum, attributed to flares of his Crohn's disease, which required treatment with steroid pulses and factor IX infusions. Ultimately, the patient was placed on daily alternating doses of prednisone $20 \mathrm{mg}$ and $50 \mathrm{mg}$. In January 2002, he presented to his hematologist and subsequently to the ED with hematochezia and hemoglobin of $6.4 \mathrm{~g} / \mathrm{dL}$. Colonoscopy revealed apthous ulcerations in the terminal ileum consistent with Crohn's disease. The bleeding was stopped with factor IX infusions and IV solumedrol. After three days the patient was discharged on budesonide $9 \mathrm{mg}$ daily, Asacol $3.5 \mathrm{~g}$ daily, and was also receiving daily injections of factor IX. Despite these efforts, he continued to bleed and required iron infusions for his profound iron deficiency anemia. Eventually, the patient's Crohn's disease was under control with alternate day prednisone at $30 \mathrm{mg}$.

The patient was doing well until December of 2003, when he again began experiencing bright red blood per rectum. He was started on azathioprine $50 \mathrm{mg}$, which was soon discontinued secondary to patient intolerance. Steroids were increased to a daily dose of prednisone $40 \mathrm{mg}$ with only mild clinical response. In May 2004, the patient was requiring factor IX infusions approximately once a month for recurrent GI bleeding. In October 2004, after discussion with the patient's hematologist and Centocor (producers of Remicade), the decision was made to treat the patient with remicade at the standard dose of $5 \mathrm{mg} / \mathrm{kg}$ at weeks 0,2 , and 6 weeks. Initially, the patient responded well with decreased GI complaints, and he achieved remission of his Crohn's disease after the third dose. He no longer had any GI bleeding and his hemoglobin stabilized at $15.3 \mathrm{~g} / \mathrm{dL}$. His prednisone dose was able to be tapered to $20 \mathrm{mg}$ every other day; further tapering is in progress. After seeing these results, the patient was continued on the maintenance dose of $5 \mathrm{mg} / \mathrm{kg}$ every 8 weeks.

\section{Discussion}

Review of the literature revealed the absence of reports of patients with concomitant Crohn's disease, hemophilia, and hepatitis C. The literature consists of information about patients who suffer from hemophilia and hepatitis $\mathrm{C}$ as a result of transfusion acquired disease, but there are no cases also involving inflammatory bowel disease. Indeed, one study performed by Thompson, et al. ${ }^{1}$ showed that the incidence of inflammatory bowel disease among patients with hemophilia and von Willebrand's disease is lower than that found in the general population. Of 6433 patients with hemophilia and 3129 patients with von Willebrand's disease, only 4 cases of Crohn's disease were detected while the expected number of cases was 11.97-16.58. This study suggests that thrombotic events play a role in the development of inflammatory bowel disease, and therefore, hemophilia protects against IBD. ${ }^{2}$

Although there are a large number of patients who have Crohn's disease who are also infected with hepatitis B and/or hepatitis C as a result of frequent endoscopic and surgical procedures, there are relatively few reported cases of patients with $\mathrm{HBV}$ or $\mathrm{HCV}$ who have been treated with infliximab (Remicade, Centocor) for control of Crohn's disease. ${ }^{3}$ Infliximab is a monoclonal antibody directed against tumor necrosis factor alpha (TNF $\alpha$ ), which is a proinflammatory agent. TNF $\alpha$ is present in abnormally increased amounts in inflammatory liver diseases such as chronic hepatitis $\mathrm{B}$ and $\mathrm{C}$ as well as autoimmune and alcoholic hepatitis. It has been suggested that up regulation of TNF $\alpha$ may encourage clearance of hepatitis B virus. ${ }^{4}$ Therefore, it has been postulated that treating patients with concomitant hepatitis $\mathrm{B}$ or $\mathrm{C}$ and Crohn's disease with infliximab would increase the amount of circulating virus and induce reactivation. Even so, the overall consensus in the literature until recently was that immunomodulating drugs used for the treatment of Crohn's disease did not alter the course of patients with coexisting hepatitis B or hepatitis C. ${ }^{5}$ In 2004, two case reports addressed this issue among four cases of patients with hepatitis B and Crohn's disease. These four patients were treated with infliximab in standard doses of $5 \mathrm{mg} / \mathrm{kg}$, and two of them experienced acute flare of chronic hepatitis B after withdraw of infliximab therapy. ${ }^{6-7}$ One of these patients died as a result. The two patients who did not experience a flare of hepatitis $\mathrm{B}$ had been treated with lamivudine $100 \mathrm{mg}$ daily during treatment, which supports its use to prevent reactivation of hepatitis B. Among three cases of patients with concomitant 
hepatitis C and Crohn's disease who were treated with infliximab in standard doses, none experienced reactivation of hepatitis C. ${ }^{8-9}$

After review of the literature and discussion of treatment strategies with hematology, hepatology, and Centocor, the decision was made to treat our patient with infliximab due to the frequency and severity of his Crohn's disease flares. The patient's encouraging response to infliximab has supported the claim that infliximab is safe in patients with hepatitis $\mathrm{C}$ and hemophilia without adverse effects on either concomitant illness.

\section{References}

1. Thompson N, Wakefield A, and Pounder R. Inherited disorders of coagulation appear to protect against inflammatory bowel disease. Gastro 1995; 108:1011-1015.

2. Langman M. Can incoagulable blood protect against inflammatory bowel disease? Gastro 1995; 108: 1305-1307.
3. Biancone L, Pavia M. Del Vecchio Blanco G, et al. Hepatitis B and C virus infection in Crohn's disease. Inflammatory Bowel Diseases 2001; 7(4):287-294.

4. Marinos G, Naoumov N, Rossol S, et al. Tumor necrosis factor receptors in patients with chronic hepatitis B infection. Gastro 1995; 108:1453-1463.

5. Biancone L, Del Vecchio Blanco G, and Pallone F. Immumomodulatory drugs in Crohn's disease patients with hepatitis B or C virus infection. Gastro 2002; 122(2): 593-594.

6. Esteve M, Saro C, Gonzalez-Huix F. Chronic hepatitis B reactivation following infliximab therapy in Crohn's disease patients: need for primary prophylaxis. Gut 2004; 53:1363-1365

7. del Valle Garcia-Sanchez M, Gomez-Camacho F, Poyato-Gonzalez A. Infliximab therapy in a patient with Crohn's disease and chronic hepatitis B virus infection. Inflammatory Bowel Diseases 2004; 10(5): 701-702.

8. Campbell S and Ghosh S. Infliximab therapy for Crohn's disease in the presence of chronic hepatitis C infection. European J of Gastro \& Hepatol 2001; 13(2):191-192.

9. Holtman M, Galle P and Neurath M. Treatment of patients with Crohn's disease and concomitant chronic hepatitis $\mathrm{C}$ with a chimeric monoclonal antibody to TNF. Amer J of Gastro 2003; 98(2):504-505.

\section{For 100 years, patients first.}

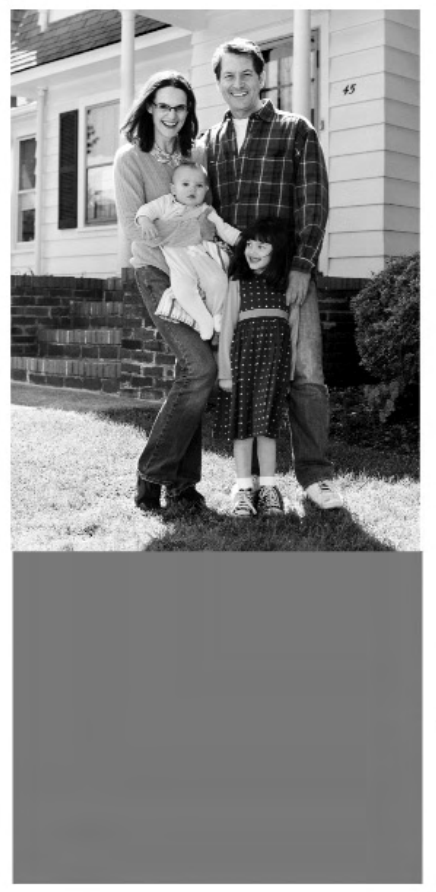

Merck is a global research-driven pharmaceutical company dedicated

to putting patients first in all we do. That philosophy was first articulated

by George Merck and it still guides us today. For nearly 100 years, Merck has discovered, developed, manufactured and marketed novel medicines and vaccines that have delivered true advances in patient care for people around the world. We continue to do the same today, but now in more than 20 therapeutic categories.

As part of our ongoing commitment to patients, Merck devotes extensive efforts to get our medicines to those who need them regardless of their ability to pay for them, and we make free, unbiased health information available to everyone.

\section{Where patients come first 8 MERCK}

